\title{
TRANS-ABDOMINAL PRE-PERITONEAL (TAPP) REPAIR FOR INGUINAL HERNIAS: A FIVE YEARS EXPERIENCE IN A TERTIARY CARE HOSPITAL
}

\author{
Nisar Ahmed, Mohammad Nadeem, Mahmud Aurangzeb \\ 'Department of Surgical Khyber Teaching Hospital, Peshawar - Pakistan
}

\begin{abstract}
Objective: To evaluate the efficacy of Transabdominal pre-peritoneal repair in the treatment of inguinal hernias.

Material and Methods: This retrospective study was conducted in Surgical A Unit, Khyber Teaching Hospital from January 2015 to December 2019. A total 114 patients were included in the study. All of the patients underwent Laparoscopic Trans-abdominal pre-peritoneal (TAPP) repair. After six months follow up, their outcome variables were analysed.

Results: Mean age of the study population was 41 ( $\pm 7.8 \mathrm{SD}$ ) years (range 21-67 years). one-hundred and four patients had unilateral while 10 patients had bilateral hernias. Eighty nine (78.07\%) patients had primary hernia while $25(21.92 \%)$ patients had recurrent hernia. Mean postoperative hospital stay was 1.21 ( $\pm 0.3 \mathrm{SD})$ days. Umbilical port infection was noted in $2(1.75 \%)$ patients while no case of deep/mesh infection was noted. Recurrence was noted in one case only. Chronic groin pain was noted in 5 (4.38\%) cases.
\end{abstract}

Conclusion: TAPP is a safe and effective treatment modality for the treatment of primary and recurrent inguinal hernias.

Keywords: Trans abdominal pre peritoneal, TAPP, Inguinal Hernia.

This article may be cited as: Ahmed N, Nadeem M, Aurangzeb M. Trans-abdominal pre-peritoneal (TAPP) repair for Inguinal Hernias: A five years experience in a Tertiary Care Hospital. J Med Sci 2021 January;29(1):48-51

\section{INTRODUCTION}

Inguinal Hernia repair is one of the commonest procedures done in the general surgical practice ${ }^{1}$. The lifetime risk of developing a groin hernia (inguinal or femoral) is $27-43 \%$ in men, and $3-6 \%$ in women ${ }^{2}$. The history of evolution of the surgical procedures over the last two centuries has been an interesting topic, and the repair options continue to be in the process of evolution ${ }^{3}$. With the advent of laparoscopic surgery, surgeons developed a renewed interest in the understanding of mechanics and pathophysiology of hernia and thus led to the development of laparoscopic procedures for repair of the same. Two laparoscopic procedures have found their way into the guidelines for treatment of hernias; the Trans-Abdominal Pre-peritoneal (TAPP) repair, and the Totally Extra-Peritoneal (TEP) repair ${ }^{4,5}$. These procedures have found an established role in the treatment of primary as well as recurrent hernias ${ }^{1,6}$. The outcome of both TAPP and TEP repairs appears to be similar, therefore, the choice between

\section{Correspondence}

Dr. Nisar Ahmed

Department of Surgery, Khyber Teaching Hospital,

Peshawar - Pakistan

Email:drnisar@hotmail.com

Cell:+92-321-5113569

Date received: $\quad 27-12-2020$

Date revised: 20-10-2021

Date accepted: 20-12-2021 the two procedures depends mainly on the surgeon's preference and expertise ${ }^{7,8,9}$.

Whereas the international studies and guidelines have been documenting the efficacy and safety profile of the laparoscopic techniques, the local data about such experience is limited.

In Khyber Teaching Hospital, the TAPP technique has been in practice for more than seven years. In this study an effort is made to objectively determine the outcome of hernia surgery with this technique.

\section{MATERIAL AND METHODS}

This retrospective study was conducted in Surgical A Unit, Khyber Teaching Hospital Peshawar, from 1st January 2015 to 31 st December 2019. Records of the patients who underwent TAPP repair were examined for admission data, pre operative diagnosis, presence or absence of co-morbids, operative notes and follow up records. All the patients whose records were complete were included in the study; those patients in whom the follow-up visits were not documented were excluded.

All the procedures were performed under general anesthesia in supine position. The surgeon's position was on the side opposite to the hernia while the monitor's position on the side of hernia. Three port technique was used in all the cases. Abdominal entry was done through 
Trans-Abdominal Pre-Peritoneal (Tapp) Repair For Inguinal Hernias: A Five Years Experience In A Tertiary Care Hospital.

Hasson's technique via a $10 \mathrm{~mm}$ supra-umbilical incision. Two additional $5 \mathrm{~mm}$ ports were used in the right and left midclavicular lines, aligned horizontally with the umbilicus. The mesh used in all the cases was $10 \times 15 \mathrm{~cm}$ polypropylene macro-pore mesh. Fixation of mesh was done to the anterior abdominal wall at minimum three points and to the Cooper's ligament with titanium endo-tacker (mesh fixation device). Peritoneal defect was closed in all the cases with polyglactin $2 / 0$ continuous suture.

Post-operatively, the patients were kept in ward, and their mobilisation and oral intake were encouraged on the same day. The outcome variables studied were; hospital stay, wound infection, mesh infection, inguinal pain and recurrence.

\section{RESULTS}

A total number of 129 patients were operated during the 5 year interval by the principal author (single operator). Fifteen patients were excluded from the study because of absence of follow up documentation. All the patients were male, mean age was $42( \pm 7.8 \mathrm{SD})$ with age range from 21 to 67 years. Characteristics of the hernia are described in Table 1

The mean post operative hospital stay in the patients was 1.21 ( \pm 0.3 days). Umbilical port site discharge was noted in 5 (4.38\%) patients, among whom infection was documented in $2(1.75 \%)$ patients. No case of mesh infection was noted among our study population. Recurrence at six months follow up was noticed in one patient.

Table 1: Characteristics of Hernia

\begin{tabular}{|c|c|c|}
\hline Type of Hernia & $\mathbf{n}$ & $\%$ \\
\hline \multicolumn{3}{|c|}{ Laterality } \\
\hline Right & 62 & 54.38 \\
\hline Left & 42 & 36.84 \\
\hline Bilateral & 10 & 8.77 \\
\hline \multicolumn{3}{|c|}{ Primary/Recurrent } \\
\hline Primary & 89 & 78.07 \\
\hline Recurrent & 25 & 21.92 \\
\hline \multicolumn{3}{|c|}{ Hernia Type (Medial/Lateral/Femoral) } \\
\hline $\begin{array}{l}\text { Hernia Type (Medial/ } \\
\text { Lateral/Femoral) }\end{array}$ & 73 & 58.8 \\
\hline Lateral(Indirect) & 41 & 33.1 \\
\hline Medial(Direct) & 10 & 8.1 \\
\hline $\begin{array}{l}\text { Medial/Lateral(Panta- } \\
\text { Ioon) }\end{array}$ & 0 & 0 \\
\hline Femoral & & \\
\hline
\end{tabular}

Chronic groin pain was reported by 5 (4.38\%) of the patients, among them one patient developed osteitis pubis. No mortality was observed in our study.

\section{DISCUSSION}

Hernia repair has been one of the greatly debated areas of general surgery. The success of surgical treatment of hernia is generally described in terms of recurrence rates. All the historical improvements in hernia surgery have been aimed at reducing the recurrence ${ }^{10}$.

In pursuit of this aim, the most successful intervention strategy used till date has been the introduction of prosthetic mesh. The results of using a mesh have been reproducible and the recurrence rates have been minimized. Therefore, the different hernia treatment guidelines recommend placement of prosthetic mesh as the primary modality of treatment ${ }^{6}$. But with the mesh usage, a different type of subset of complications have been added to the measurement of outcome of hernia surgery i.e. mesh infection and chronic groin pain. In our study, the main outcome variables have been recurrence, mesh infection and chronic groin pain.

We noticed umbilical discharge in 5 (4.38\%) cases and swabs were taken from the affected wounds for bacterial culture and antibiotic sensitivity. Among those cases Staphyllococcus aureus was isolated in two (1.75\%) cases only. Those cases were treated with Amoxicillin-Clavulinic acid successfully. In the literature, the incidence of port site discharge after laparoscopic surgery has been described, and is often attributed to extraction of specimen ${ }^{11,12}$. As in case of hernia surgery, no contaminated specimen is extracted through the port site. Therefore, the frequency of port site discharge is minimal. For prevention of infection, the recommendations include use of disposable trocars where possible ${ }^{11}$. In our series, we used reusable metallic trocars.

Mesh infection has been a dreadful complication of inguinal hernia surgery. Systemic reviews of TAPP repair reveal mesh infection in up to $0.2 \%$ cases $^{13,14}$. In our study, no case of mesh infection was noted. Though a rare complication, its treatment can be a tedious task and could require explantation of the mesh ${ }^{15}$.

In our follow up period of six months, recurrence was noted in one $(0.87 \%)$ case. Recurrence rates of less than one percent have been reported in a variety of studies $^{13,14,16}$.

Chronic groin pain can be a troublesome feature after repair of inguinal hernia. With the advent of the Laparoscopic approach, this incidence seems to be significantly less $(2.4 \%$ cases experienced limitation in daily activities due to pain) as compared to the open mesh techniques ${ }^{17}$. In our series, we observed chronic pain in 5 (4.38\%) patients, among those, one patient had a persistent crippling pain in the inguinal region, limiting his mobility to bed. MRI and CT scan were suggestive of osteitis pubis and the patient responded to a course of Fusidic acid and Ofloxacin. In the literature, numerous cases of the same have been 
Trans-Abdominal Pre-Peritoneal (Tapp) Repair For Inguinal Hernias: A Five Years Experience In A Tertiary Care Hospital.

reported, though the exact incidence remains uncertain and is often attributed to fixation of mesh to pubic bone bi,19. $^{18}$.

In our series, we operated on 10 cases of recurrent hernias where the initial surgeries performed were either Lichtenstein $(n=7)$, Bassini $(n=1)$, or had multiple and a variety of repairs $(n=2)$. During the course of surgery, it was noted that for such surgeries, the approach from the intra-abdominal side provided a relatively untouched area with minimal fibrosis and thus making the surgery convenient and all the surgical landmarks easily identifiable. The outcome in these cases was excellent. Perhaps for this reason, various guidelines have recommended the Laparoscopic technique for repair of hernia to be the primary modality of treatment in case of recurrent hernias where the initial surgery has been through the anterior approach $^{1,6}$.

\section{CONCLUSION}

TAPP (Trans-abdominal pre-peritoneal) repair of inguinal hernia is a safe and effective modality for the treatment of primary and recurrent inguinal hernias. It provides an excellent approach to bilateral hernias. Because of the small percentage of complications, studies with a large sample size would be more appropriate to determine the precise outcome. In our opinion, TAPP repair should be considered the primary modality of treatment for recurrent hernias.

\section{REFERENCES}

1. Simons MP, Aufenacker T, Bay-Nielsen M, Bouillot JL, Campanelli G, Conze J, et al. European Hernia Society guidelines on the treatment of inguinal hernia in adult patients. Hernia [Internet]. 2009 Aug 28 [cited 2020 Jun 21];13(4):343-403. Available from: https://link.springer. com/article/10.1007/s10029-009-0529-7

2. Köckerling F, Simons MP. Current Concepts of Inguinal Hernia Repair. Visceral Medicine [Internet]. 2018 Apr 1 [cited $2020 \mathrm{Jul} 2$ ];34(2):145-50. Available from: https:// www.karger.com/Article/FullText/487278

3. Lau WY. History of treatment of groin hernia. World Journal of Surgery [Internet]. 2002 Jun [cited 2020 Jun 24];26(6):748-59. Available from: http://link.springer. com/10.1007/s00268-002-6297-5

4. Miserez M, Peeters E, Aufenacker T, Bouillot JL, Campanelli G, Conze J, et al. Update with level 1 studies of the European Hernia Society guidelines on the treatment of inguinal hernia in adult patients. Hernia [Internet]. 2014 Apr 20 [cited $2020 \mathrm{Jul}$ 2];18(2):151-63. Available from: http://link.springer.com/10.1007/s10029-014-1236-6

5. Bittner R, Arregui ME, Bisgaard T, Dudai M, Ferzli GS, Fitzgibbons RJ, et al. Guidelines for laparoscopic (TAPP) and endoscopic (TEP) treatment of inguinal hernia [International Endohernia Society (IEHS)]. In: Surgical endoscopy. 2011. 2773-843.

6. Simons MP, Smietanski M, Bonjer HJ, Bittner R, Miserez $\mathrm{M}$, Aufenacker TJ, et al. International guidelines for groin hernia management. Hernia [Internet]. 2018 Feb 12 [cit- ed 2020 Jun 21];22(1):1-165. Available from: http://link. springer.com/10.1007/s10029-017-1668-x

7. Wei FX, Zhang YC, Han W, Zhang YL, Shao Y, Ni R. Transabdominal Preperitoneal (TAPP) Versus Totally Extraperitoneal (TEP) for Laparoscopic Hernia Repair. Surgical Laparoscopy, Endoscopy \& Percutaneous Techniques [Internet]. 2015 Oct 11 [cited 2020 Jun 24];25(5):37583. Available from: http://journals.Iww.com/00129689201510000-00001

8. $\mathrm{Qu} \mathrm{K}, \mathrm{Ma}$ J. Comments on "Transabdominal Preperitoneal (TAPP) Versus Totally Extraperitoneal (TEP) for Laparoscopic Hernia Repair. Surgical Laparoscopy, Endoscopy \& Percutaneous Techniques [Internet]. 2016 Apr [cited 2020 Jun 24];26(2):171. Available from: http:// journals.Iww.com/00129689-201604000-00014

9. Köckerling F, Bittner R, Kuthe A, Hukauf M, Mayer F, Fortelny $\mathrm{R}$, et al. TEP or TAPP for recurrent inguinal hernia repair-register-based comparison of the outcome. Surgical Endoscopy [Internet]. 2017 Oct 3 [cited 2020 Jun 24];31(10):3872-82. Available from: http://link.springer. com/10.1007/s00464-017-5416-1

10. Read RC. The preperitoneal approach to the groin and the inferior epigastric vessels. Hernia [Internet]. 2005 Mar 5 [cited 2020 Jul 2];9(1):79-83. Available from: http://link.springer.com/10.1007/s10029-004-0240-7

11. Sasmal PK. Port site infection in laparoscopic surgery: $A$ review of its management. World $\mathrm{J}$ Clinical Cases [Internet]. 2015 [cited $2020 \mathrm{Jul} 4$ ];3(10):864. Available from: http://www.wjgnet.com/2307-8960/full/v3/i10/864.htmh

12. Hamzaoglu I, Baca B, B??ler DE, Polat E, ??zer Y. Is Umbilical Flora Responsible for Wound Infection After Laparoscopic Surgery? Surgical Laparoscopy, Endoscopy \& Percutaneous Techniques [Internet]. 2004 Oct 1 [cited 2020 Jul 4];14(5):263-7. Available from: http://journals. Iww.com/00129689-200410000-00007

13. McCormack K, Wake BL, Fraser C, Vale L, Perez J, Grant A. Transabdominal pre-peritoneal (TAPP) versus totally extraperitoneal (TEP) laparoscopic techniques for inguinal hernia repair: a systematic review. Hernia [Internet]. 2005 May 10 [cited 2020 Jul 4];9(2):109-14. Available from: http://link.springer.com/10.1007/s10029-004-03093

14. Wake BL, McCormack K, Fraser C, Vale L, Perez J, Grant A. Transabdominal pre-peritoneal (TAPP) vs totally extraperitoneal (TEP) laparoscopic techniques for inguinal hernia repair. Cochrane Database of Systematic Reviews [Internet]. 2005 Jan 24 [cited 2020 Jul 4]; Available from: http://doi.wiley.com/10.1002/14651858.CD004703.pub2

15. Yang H, Liu Y, Chen J, Shen Y. The Management of Mesh Infection After Laparoscopic Inguinal Hernia Repair. Surgical Laparoscopy, Endoscopy \& Percutaneous Techniques [Internet]. 2019 Feb 1 [cited 2020 Jul 4];29(1):40-2. Available from: http://journals.Iww. com/00129689-201902000-00009

16. Kapiris SA, Brough WA, Royston CMS, O'Boyle C, Sedman PC. Laparoscopic transabdominal preperitoneal (TAPP) hernia repair: A 7-year two-center experience in 3017 patients. In: Surgical Endoscopy [Internet]. Springer; 2001 [cited 2020 Jul 2]. p. 972-5. Available from: https://link.springer.com/article/10.1007/s004640080090 
Trans-Abdominal Pre-Peritoneal (Tapp) Repair For Inguinal Hernias: A Five Years Experience In A Tertiary Care Hospital.

17. Koninger J, Redecke J, Butters M. Chronic pain after hernia repair: a randomized trial comparing Shouldice, Lichtenstein and TAPP. Langenbeck's Archives of Surgery [Internet]. 2004 Oct 9 [cited 2020 Jul 2];389(5):3615. Available from: http://link.springer.com/10.1007/ s00423-004-0496-5

18. Tashiro Y, Murakami M, Fukoe Y, Lee Y, Lee M. Pubic osteomyelitis after transabdominal preperitoneal inguinal hernia repair. Hernia [Internet]. 2017 Oct 5 [cited 2020 Jul 5];21(5):813-5. Available from: http://link.springer. com/10.1007/s10029-017-1599-6

19. Sajid MS, Ladwa N, Kalra L, McFall M, Baig MK, Sains P. A meta-analysis examining the use of tacker mesh fixation versus glue mesh fixation in laparoscopic inguinal hernia repair. Amer J Surgery [Internet]. 2013 Jul 1 [cited 2020 Jul 5];206(1):103-11. Available from: https://linkinghub.elsevier.com/retrieve/pii/S0002961013000263
CONFLICT OF INTEREST: Authors declare no conflict of interest

GRANT SUPPORT AND FINANCIAL DISCLOSURE: NIL

\section{AUTHOR'S CONTRIBUTION}

Following authors have made substantial contributions to the manuscript as under

Ahmed N: Concept, Design, Analysis and interpretation of data.

Nadeem M: Data collection and critical review.

Aurangzeb M: Proof reading.

Authors agree to be accountable for all aspects of the work in ensuring that questions related to the accuracy or integrity of any part of the work are appropriately investigated and resolved. 